\title{
Retinopathy in Newly Diagnosed Type 2 Diabetes mellitus
}

\author{
Homoud Al-Zuabi ${ }^{\mathrm{a}}$ Yaqoub Al-Tammar ${ }^{\mathrm{b}}$ Reem Al-Moataz ${ }^{\mathrm{b}}$ \\ Khalid Al-Sabti ${ }^{\text {d }}$ Vivek B. Wani $^{\mathrm{e}}$ Fahad Hamama ${ }^{\mathrm{a}}$ Hanan Mohammad \\ Mai H. Al-Suwayan ${ }^{\mathrm{C}}$ \\ ${ }^{a}$ Department of Primary Health Care, Farwania Health Area, ${ }^{b}$ Department of Primary Health Care and \\ ${ }^{\mathrm{c}}$ Department of Preventive Medicine, Asma Health Area, ${ }^{\mathrm{d}}$ Department of Surgery, Faculty of Medicine, \\ Kuwait University, and ${ }^{\text {e}}$ Department of Ophthalmology, Ibn Sina Hospital, Kuwait
}

\section{Key Words}

Diabetic retinopathy - Type 2 diabetes mellitus •

Complications · Primary care

\begin{abstract}
Objective: To study the prevalence of diabetic retinopathy and its association with risk factors in newly diagnosed type 2 diabetic patients in two primary care diabetic clinics in Kuwait. Subjects and Methods: All newly diagnosed type 2 diabetes mellitus patients attending Ferdous and Yarmouk Health Care Diabetic Clinics in Farwaniya and Asma Health Areas, respectively, during the period of January 2002 to July 2004 were examined for the presence of diabetic retinopathy by color fundus photographs. Risk factors such as sex, age, hypertension, nephropathy, hyperglycemia, level of glycated hemoglobin, microalbuminuria and hyperlipidemia were evaluated by statistical analysis for their possible association with the presence of diabetic retinopathy at the time of diagnosis of diabetes. Results: Of the 92 newly diagnosed type 2 diabetes mellitus patients studied, diabetic retinopathy was present in $7(7.6 \%)$ patients. Two of the 7 patients had maculopathy that needed treatment by photocoagulation. High glycated hemoglobin in 51
\end{abstract}

patients (55.4\%), microalbuminuria in 25 (27.2\%), hypertension in 29 (315\%), hyperlipidemia in 69 (75\%), obesity in $45(48.9 \%)$ and overweight in $37(40.2 \%)$ were noted in the study population. Microalbuminuria was weakly associated with the presence of retinopathy $(p=0.08)$ at the time of diagnosis of diabetes mellitus, but other risk factors were not statistically significant. Conclusions: Prevalence of diabetic retinopathy was $7.6 \%$ among the study population. Maculopathy was present in 2 of the 7 patients needing photocoagulation.

Copyright $(2005$ S. Karger AG, Basel

\section{Introduction}

Diabetic retinopathy (DR) is a specific microvascular complication of diabetes mellitus (DM) and is the leading cause of new blindness among American adults aged 2074 years [1]. However, blindness due to DR can be prevented if the DR is detected early and treated by photocoagulation $[2,3]$. The importance of screening the diabetic patients for DR and its cost-effectiveness has been proven in several studies $[4,5]$. However, since type 2 DM may be present well before its clinical diagnosis is made [6], it is not uncommon to see the microvascular

\section{KARGER}

Fax +4161306 1234

E-Mail karger@karger.ch

www.karger.com
(C) 2005 S. Karger AG, Basel

1011-7571/05/0145-0293\$22.00/0

Accessible online at:

www.karger.com/mpp
Dr. Homoud Al-Zuabi

PO Box 2326

92400 Ardiya (Kuwait)

Tel. +965 4883268, Fax +9654883268

E-Mail alzeabi@hotmail.com 
complications of type $2 \mathrm{DM}$ at the time of diagnosis. Reported prevalence rates of DR at the time of diagnosis of type 2 diabetes vary from 5 to $35 \%$ [7-15]. In several studies the risk factors associated with the presence of DR at the time of diagnosis of DM have been identified [10, 11, $13,15]$. Elevated body mass index (BMI) [10], lower BMI [11], elevated blood pressure [10,13,15], raised levels of glycated hemoglobin $\left(\mathrm{HbA}_{1 \mathrm{c}}\right)$ [11], elevated cholesterol level [10], elevated fasting plasma glucose levels [15] and reduced $\beta$-cell function [15] are some of the risk factors that have been identified. In Kuwait approximately $15.35 \%$ of the population in the 40- to 59-year age group and $26.2 \%$ in the 60 years and above have non-insulindependent DM [16]. Because of the high prevalence rates of type $2 \mathrm{DM}$ in Kuwait, there is a need for baseline data regarding the prevalence of DR among newly diagnosed type $2 \mathrm{DM}$ patients. Therefore, this study was undertaken to assess the prevalence rates of DR and the associated risk factors for its presence among the newly diagnosed type 2 DM patients in Kuwait.

\section{Subjects and Methods}

This was a prospective, noncomparative study carried out at Ferdous and Yarmouk Primary Health Care Clinics in Farwaniya and Asma Health Areas, respectively, that included 92 patients with type $2 \mathrm{DM}$. These two primary clinics cover a population of 150,000 . All the newly diagnosed type $2 \mathrm{DM}$ patients referred from the general practitioners to the diabetic clinics between the period of January 2002 to July 2004 were enrolled in the study. They were taken in a sequential manner, provided that their medical records have been reviewed for any evidence of abnormal glucose test results in the past 5 years. The criteria for diagnosis of type 2 DM were according to the World Health Organization recommended guidelines, 1994 [17]. Fifty-two patients were females and 40 males. The average age was 51.9 years (range $30-70$ years, SD \pm 9.4 ). Seventy-one were Kuwaiti nationals and 21 were other nationals. Eighteen were current and former smokers.

Data regarding age, sex, occupation, nationality, history of smoking and hypertension were obtained from the medical records and recorded in a special data sheet designed for the study. Although all the patients were asymptomatic regarding vision, they underwent color fundus photography of both eyes after dilatation of the pupils. Color fundus photographs were taken by a trained diabetologist on a Canon CR 45 digital camera and stored as computerized digital images. The photographs were then examined later, by 2 ophthalmologists on the same computer, for the assessment of status of DR. If DR was present, the severity of the retinopathy in each eye was determined for each patient according to a standard protocol. The retinopathy was graded into: background, background with maculopathy, preproliferative, proliferative, and advanced proliferative DR [18].

The patients were assessed for the presence of other risk factors: hyperglycemia, nephropathy, hypertension, hyperlipidemia, smok- ing and obesity. The degree of hyperglycemia was evaluated by measuring $\mathrm{HbA}_{1 \mathrm{c}}$ concentration. Optimal glycemic control was considered an $\mathrm{HbA}_{1 \mathrm{c}}<7 \%$. Microalbuminuria level was measured in early morning urine first void sample, to assess the presence of nephropathy (normal value $<19 \mathrm{mg} / \mathrm{l}$ ). The urine test was repeated twice 2-4 weeks apart and other causes of microalbuminuria were excluded. The presence of hypertension was recorded from the patient's file. A patient was considered hypertensive according to the WHO criteria of sustained systolic blood pressure of $140 \mathrm{~mm} \mathrm{Hg}$ or diastolic blood pressure of $90 \mathrm{~mm} \mathrm{Hg}$ or both, or if the patient was on antihypertensive treatment. Hyperlipidemia was determined from blood samples taken after 12-hour fasting according to WHO criteria [10]. Hyperlipidemia was considered to be present if the patient had high total cholesterol level $(>5.2 \mathrm{mmol} / \mathrm{l})$, elevated low-density lipoprotein $(>4.5 \mathrm{mmol} / \mathrm{l})$ levels, high triglyceride levels $(>2.28 \mathrm{mmol} / \mathrm{l})$ or low high-density lipoprotein $(<1 \mathrm{mmol} / \mathrm{l})$.

Height was measured without shoes to the nearest $0.5 \mathrm{~mm}$ and weight was measured to the nearest $0.1 \mathrm{~kg}$, with the subject in light clothes, pockets emptied with and without shoes. As recommended by the WHO, the standard classification of overweight and obesity was based on the following calculation of BMI = weight $/$ height $^{2}$. A BMI of $25-29.9 \mathrm{~kg} / \mathrm{m}^{2}$ was regarded as overweight, a BMI of $30 \mathrm{~kg} / \mathrm{m}^{2}$ and more as obesity. A BMI of 30-34.9, 35-39.9 and $\geq 40 \mathrm{~kg} / \mathrm{m}^{2}$ was defined as class I, class II, class III obesity, respectively [19].

The patients with newly diagnosed type $2 \mathrm{DM}$ were divided into two groups: those with any DR and those without DR. The role of risk factors for the presence of DR was evaluated by statistical analysis by $\chi^{2}$ test using the software of Statistical Package of Social Studies SPSS 11.0.

\section{Results}

DR was detected in 7 patients (7.6\%), 6 in both eyes and 1 in one eye. Five were female and remaining 2 male; average age was $51 \pm 10.4$ years. All the 7 patients with DR were nonsmokers and had background DR with 2 of them having additional bilateral maculopathy. Evaluation of macula with slit lamp biomicroscopy with contact lens examination showed the maculopathy to be clinically significant in both cases and needed focal laser treatment. Uncontrolled $\mathrm{HbA}_{1 \mathrm{c}}$ was present in 51 (55.4\%), microalbuminuria in $25(27.2 \%)$, hypertension in 29 $(31.5 \%)$ and hyperlipidemia in 69 patients $(75 \%)$. Obesity was present in $45(48.9 \%)$ patients and overweight in $37(40.2 \%)$ patients (giving a total overweight patients of $82,89.1 \%)$.

The difference in the risk factors between the 7 patients with and those without DR was not statistically significant (table 1, $\mathrm{p}>0.05$ ). 
Table 1. Risk factors studied for the presence of retinopathy in newly diagnosed type $2 \mathrm{DM}$

\begin{tabular}{|c|c|c|c|}
\hline Variable & $\begin{array}{l}\text { DR present } \\
(\mathrm{n}=7)\end{array}$ & $\begin{array}{l}\text { DR absent } \\
(\mathrm{n}=85)\end{array}$ & $\begin{array}{l}\mathrm{p} \\
\text { value }^{1}\end{array}$ \\
\hline Age (>51 years) & $4(57.1 \%)$ & $48(56.47 \%)$ & 0.95 \\
\hline Sex (male) & $2(28.6 \%)$ & $38(44.7 \%)$ & 0.40 \\
\hline Sex (female) & 5 & 47 & \\
\hline Smokers & $0(0 \%)$ & $18(21.2 \%)$ & 0.17 \\
\hline Nonsmokers & 7 & & \\
\hline Kuwaiti & $4(57.1 \%)$ & $67(78.8 \%)$ & 0.18 \\
\hline Non-Kuwaiti & 3 & & \\
\hline High $\mathrm{HbA}_{1 \mathrm{c}}$ & $6(85.7 \%)$ & $45(52.9 \%)$ & 0.19 \\
\hline Hypertension & $2(28.6 \%)$ & $27(31.7 \%)$ & 0.86 \\
\hline Hyperlipidemia & $6(85.7 \%)$ & $63(74.1 \%)$ & 0.49 \\
\hline Microalbuminuria & $4(57.1 \%)$ & $21(24.7 \%)$ & 0.08 \\
\hline Obesity & $3(42.8 \%)$ & $42(49.4 \%)$ & 0.49 \\
\hline Overweight & $4(57.1 \%)$ & $33(38.8 \%)$ & 0.49 \\
\hline
\end{tabular}

${ }^{1} \mathrm{p}$ value $<0.05$ considered significant.

\section{Discussion}

The relatively low rate of DR (7.6\%) among newly diagnosed type $2 \mathrm{DM}$ patients in this study is similar to those of other studies that include Denmark (5\%) [7], Australia (6.2\%) [8] and South India (7.3\%) [9], but not to Romania (14.37\%) [12], Taiwan (25.5\%) [14] and the UKPDS group in the United Kingdom (35\%) [15]. Although it is difficult to identify the reasons for such variation in prevalence rates among various populations, race, age, method of detecting DR, health care facilities, and other risk factors could have contributed to the differences.

Some studies have shown that older age at diagnosis of DM is a risk factor for the presence of DR [13, 20,21], which could account for the differences in the prevalence of DR in the previously cited studies [present study, 7-9, $12,14,15]$. This observation may probably be due to the fact that diabetes in older individuals may be present for a longer time before it is diagnosed. In the present study gender was not a significant factor for the presence of DR as observed in other studies [11, 13], but Liu et al. [21] reported gender as a risk factor for the presence of DR at the time of diagnosis of type $2 \mathrm{DM}$.

$\mathrm{HbA}_{1 \mathrm{c}}$ level is regarded as the gold standard indicator for the level of glycemic control, and clinical trials have shown that decreasing $\mathrm{HbA}_{1 \mathrm{c}}$ levels by $1 \%$ point would reduce microvascular complications by $25 \%$ [22]. Although 6 out of 7 patients with DR in this study had high levels of $\mathrm{HbA}_{1 \mathrm{c}}$, the correlation was not statistically significant $(p>0.19)$. However, Nguyen et al. [11] and Owens et al. [13] have shown that higher $\mathrm{HbA}_{1 \mathrm{c}}$ is a risk factor for the presence of DR among newly diagnosed cases of type $2 \mathrm{DM}$ patients. Equally important, Van Leiden et al. [10] have also shown that DR may be present in individuals with only impaired glucose tolerance without the diagnosis of type $2 \mathrm{DM}$, thereby validating the observation that type $2 \mathrm{DM}$ and indeed DR may be present for several years before it is diagnosed clinically [6].

The other biochemical parameters (hyperlipidemia [10] and microalbuminuria [7, 14, 23, 24]) reported to be positively associated with DR in newly diagnosed type 2 DM patients appeared to have not had such an association in this study similar to Rema et al. [9] and Nguyen et al. [11]. In point of fact 6 of the 7 patients with DR of this study had high lipid levels. It is important to point out that albuminuria was present in 4 of our 7 patients (57.1\%) with DR compared to 21 of $85(24.7 \%)$ without DR. Despite the difference in albuminuria between patients with and without DR ( $p>0.08)$, there was a trend with increasing level of albuminuria with DR in this study. The other risk factors of hypertension, BMI and smoking were also not associated with DR, although hypertension is a recognized risk factor in type $2 \mathrm{DM}$ patients with DR [10, 13, 15]. Van Leiden et al. [10] reported positive association with BMI while Nguyen et al. [11] and Owens et al. [13] reported negative association. Surprisingly the UKPD study [15] showed that the severity of DR was more in leaner than obese women.

The effects of smoking on DR are equivocal [25]. However, Eliasson [26] has observed that cigarette smoking increases the risk for DR, probably via its metabolic effects in combination with increased inflammation and endothelial dysfunction, especially in type 1 diabetic patients.

Significantly, vision-threatening maculopathy was present in 2/7 cases, similar to the finding of de Fine Olivarius et al. [7]. These cases show that some patients may already be in need of treatment for the DR at the time of diagnosis of type $2 \mathrm{DM}$, thereby making it necessary to perform fundus examination in all newly discovered type 2 diabetic subjects. The digital camera used for the evaluation of DR was found reliable in diagnosing the DR as previously reported [27]. Comparison of the digital image of the fundus with clinical examination by slit lamp biomicroscopy by ophthalmologists showed a good correlation as in our previous study [27]. Digital camera allows storage of images, which can be viewed later at a convenient time thereby obviating the need for immediate re- 
ferral of the patient to the Ophthalmology Clinic unless both maculopathy and preproliferative DR are involved. This restricted referral saves time and is also cost-effective. The principal drawback of this study is the relatively small number of patients. Hence there is a need for further studies involving a larger patient population. The identification of risk factors associated with DR in our population will alert the physician to recognize a subset of type $2 \mathrm{DM}$ patients who need to be investigated for the presence of DR.

\section{Conclusions}

The prevalence of DR among the newly diagnosed type 2 diabetics was relatively low with 2 patients who had vision-threatening maculopathy at the time of diagnosis of type $2 \mathrm{DM}$.

\section{References}

1 National Society to Prevent Blindness: Visual Problems in the U.S. Data Analysis Definitions. Data Sources, Detailed Data Tables, Analysis, Interpretation. New York, National Society to Prevent Blindness, 1980, pp 1-46.

- 2 Diabetic Retinopathy Study Research Group: DRS Group Number 8. Photocoagulation treatment of proliferative diabetic retinopathy. Ophthalmology 1981;88:583-600.

-3 Early Treatment Diabetic Retinopathy Study Research Group: Photocoagulation for diabetic macular oedema. Int Ophthalmol Clin 1987; 27:265-272.

-4 Polak BC, Crijns H, Casparie AF, Niessen LW: Cost-effectiveness of glycemic control and ophthalmological care in diabetic retinopathy. Health Policy 2003;64:89-97.

$\checkmark 5$ Choremis J, Chow DR: Use of telemedicine in screening for diabetic retinopathy. Can J Ophthalmol 2003;38:575-579.

- 6 Harris MI, Klein R, Welborn TA, Knuiman MW: Onset of NIDDM occurs at least 4 to 7 years before clinical diagnosis. Diabetes Care 1992;15:815-819.

7 de Fine Olivarius N, Nielsen NV, Andreasen AH: Diabetic retinopathy in newly diagnosed middle-aged and elderly diabetic patients: prevalence and interrelationship with microalbuminuria and triglycerides. Graefes Arch Clin Exp Ophthalmol 2001;239:664-672.

8 Tapp RJ, Shaw JE, Harper CA, de Courten MP, Balkau B, McCarty DJ, Taylor HR, Welborn TA, Zimmet PZ, AusDiab Study Group: The prevalence of and factors associated with diabetic retinopathy in the Australian population. Diabetes Care 2003;26:1731-1737.

$\checkmark 9$ Rema M, Deepa R, Mohan V: Prevalence of retinopathy at diagnosis among type 2 diabetic patients attending a diabetic centre in south India. Br J Ophthalmol 2000;84:1058-1060.
10 Van Leiden HA, Dekker JM, Moll AC, Nijpels G, Heine RJ, Bouter LM, Stehouwer CD, Polak BC: Blood pressure, lipids, and obesity are associated with retinopathy: the Hoorn study. Diabetes Care 2002;25:1320-1325.

11 Nguyen HT, Luzio SD, Dolben J, West J, Beck L, Coates PA, Owens DR: Dominant risk factors for retinopathy at clinical diagnosis in patients with type II diabetes mellitus. J Diabetes Complications 1996;10:211-219.

- 12 Talu S, Kaucsar E, Soreanu A: Diabetic retinopathy in newly diagnosed patients with type II diabetes mellitus (in Romanian). Oftalmologia 2002;54:27-30.

13 Owens DR, Volund A, Jones D, Shannon AG, Jones IR, Birtwell AJ, Luzio S, Williams S, Dolben J, Creagh FN: Retinopathy in newly presenting non-insulin-dependent (type 2) diabetic patients. Diabetes Res 1988;9:59-65.

14 Tzeng TF, Hsiao PJ, Hsieh MC, Shin SJ: Association of nephropathy and retinopathy, blood pressure, age in newly diagnosed type 2 diabetes mellitus. Kaohsiung J Med Sci 2001; 17:294-301.

15 Kohner EM, Aldington SJ, Stratton IM, Manley SE, Holman RR, Matthews DR, Turner RC: United Kingdom Prospective Diabetes Study, 30: diabetic retinopathy at diagnosis of non-insulin-dependent diabetes mellitus and associated risk factors. Arch Ophthalmol 1998; 116:297-303

16 Abdella N, Khogali M, al-Ali S, Gumaa K, Bajaj J: Known type 2 diabetes mellitus among the Kuwaiti population: a prevalence study. Acta Diabetol 1996;33:145-149.

17 Prevention of diabetes mellitus: Report of a WHO Study Group. World Health Organ Tech Rep Ser 1994;844:93.

18 Central Department of Primary Health Care, Ministry of Health Kuwait: Primary Health Care Clinical Practice Guidelines Series 2001: Diabetes Mellitus, p 15.
19 Lyznicki JM, Young DC, Riggs JA, Davis RM, Council on Scientific Affairs, American Medical Association: Obesity: assessment and management in primary care. Am Fam Physician 2001;63:2185-2196.

20 Wang WQ, Ip TP, Lam KS: Changing prevalence of retinopathy in newly diagnosed noninsulin dependent diabetes mellitus patients in Hong Kong. Diabetes Res Clin Pract 1998;39: 185-191.

21 Liu DP, Molyneaux L, Chua E, Wang YZ, Wu CR, Jing H, Hu LN, Liu YJ, Xu ZR, Yue DK: Retinopathy in a Chinese population with type 2 diabetes: factors affecting the presence of this complication at diagnosis of diabetes. Diabetes Res Clin Pract 2002;56:125-131.

22 Saaddine JB, Engelgau MM, Beckles GL, Gregg EW, Thompson TJ, Narayan KM: A diabetes report card for the United States: quality of care in the 1990s. Ann Intern Med 2002;136:565.

23 Manaviat MR, Afkhami M, Shoja MR: Retinopathy and microalbuminuria in type II diabetic patients. BMC Ophthalmol 2004;4:9.

24 Gall MA, Rossing P, Skott P, Damsbo P, Vaag A, Bech K, Dejgaard A, Lauritzen M, Lauritzen E, Hougaard P: Prevalence of micro- and macroalbuminuria, arterial hypertension, retinopathy and large vessel disease in European type 2 (non-insulin-dependent) diabetic patients. Diabetologia 1991;34:655-661.

25 Jain A, Sarraf D, Fong D: Preventing diabetic retinopathy through control of systemic factors. Curr Opin Ophthalmol 2003;14:389394.

26 Eliasson B: Cigarette smoking and diabetes. Prog Cardiovasc Dis 2003;45:405-413.

- 27 Al Sabti K, Raizada S, Wani VB, Al Ajmi M, Gayed I, Sugathan TN: Efficacy and reliability of fundus digital camera as a screening tool for diabetic retinopathy in Kuwait. J Diabetes Complications 2003;17:229-233. 